\title{
Uji Aktivitas Antimikroba Ekstrak n-Butanol Madu Hutan (Apis nigrocincta) dari Kabupaten Selayar dengan Metode KLT-Bioautografi.
}

\author{
A. Suparlan Isya Samsu ${ }^{1^{*}}$, Mirfaidah Najamuddin ${ }^{1 *}$, Nurfitria Junita ${ }^{1^{*}}$, Suhra Febrina Karim ${ }^{1^{*}}$
}

${ }^{1}$ Program Studi DIII Farmasi, Fakultas Farmasi, Universitas Megarezky, Makassar, Indonesia

DOI : $\underline{\text { https://doi.org/10.29303/sjp.v1i2.34 }}$

\section{Article Info}

Received : 2020-07-26

Revised : 2020-09-28

Accepted : 2020-09-28

\begin{abstract}
Abstrak: Preliminary research has been conducted on the antimicrobial activity of nButanol extract of forest honey (Apis nigrocincta). This study aims to determine the antimicrobial activity of forest honey from Selayar Regency on the growth of test microbes, using the method of solid dilution with the test microbial Bacillus subtilis, Staphylococcus aureus, Streptococcus mutans, Pseudomonas aeruginosa, Salmonella typhi, Escherichia coli, Vibrio sp, Staphylococcus epidermidis, and Candida albicans against n-butanol extract from forest honey (Apis nigrocincta) at $1 \mathrm{mg} / \mathrm{ml}$. The results obtained showed that n-butanol extract inhibited the growth of bacteria Bacillus subtilis, Escherichia coli, Staphylococcus aureus, Staphylococcus epidermidis, and Staphylococcus aureus. To estimate the compounds that provide antimicrobial activity, TLC-Bioautography test is performed. Obtained the best results from the separation of compounds by TLC using Chlorophorom eluate: Acetone (3: 1). The TLC-Bioautographic test results showed that the spots with an Rf value of 0.29 gave activity to Bacillus subtilis, Escherichia coli, and Staphylococcus epidermidis, and gave positive results on the appearance of flavanoid compounds.
\end{abstract}

Keywords: Forest honey (Apis nigrocincta), antimicrobial, n-Butanol extract

Citation : $\quad$ Samsu, ASI., Najamuddin, M., Junita, N., Karim, SF., (2020). Uji Aktivitas Antimikroba Ekstrak n-Butanol Madu Hitam (Apis nigrocincta) dari Kabupaten Selayar dengan Metode KLT-Bioautografi. Sasambo Journal of Pharmacy, 1(2), 41-45. doi : https://doi.org/10.29303/sjp.v1i2.34

\section{Pendahuluan}

Indonesia memilki hutan alam sangat luas, sekitar 200 juta hektar, dengan berbagai jenis pohon. Pohon-pohon tersebut merupakan habitat ideal untuk kehidupan, berkembang biak, dan berproduksinya lebah madu. Lebah telah dikenal oleh masyarakat, terutama di pedesaan, sebagian masyrakat sudah melakukan budidaya lebah madu untuk meningkatkan produksi. Namun, minat masyarakat masih sangat rendah karena kurangnya pengetahuan dan anggapan bahwa usaha tersebut tidak menguntungkan. (Dewi, 2018). Indonesia memiliki spesies lebah madu yang paling beragam didunia, yaitu lima dari sembilan spesies lebah madu diantaranya madu hutan (Apis nigrocincta) yang diklaim sebagai spesies asli Indonesia (Hadisoesilo, 2001)

Madu murni merupakan kumpulan dari sari bunga yang dihasilkan dari lebah. Madu biasanya terdapat dalam sarang lebah yang berbentuk heksagon (segi enam). Untuk mendapatkan madu dari sarang lebah, biasanya para peternak memakai alat kondensor. Madu juga dapat diperoleh dengan cara diperas sarangnya hingga didapatkan madu yang jernih dan murni (Wineri, Rasyid, \& Alioes, 2014).

Pemanfaatan obat tradisional dewasa ini semakin meningkat mengikuti perkembangan tradisional sosial dan budanya masyarakat. Hal ini dapat dilihat dengan adanya berbagai bentuk obat tradisional yang beredar di masyarakat. Perkembangan tersebut menunjukkan bahwa penggunaan obat 
tradisional dari masa ke masa tidaklah menurun, tetapi meningkat terus (Wiryowidagdo, 1990).

Secara tradisional madu dipakai antara lain sebagai obat untuk antibakteri, meningkatkan stamina tubuh, merawat kulit, mengatasi kejang otot, sumber vitamin yang baik, memperkuat fungsi ginjal, menyembuhkan sakit malaria (Murtidjo, 1991).

Adapun madu hutan yang digunakan sebagai sampel penelitian ini berasal dari Kabupaten Kepulauan Selayar, Kecamatan Bontoharu dengan ketinggian 0-500 meter dari permukaan laut, sehingga jenis tanaman yang dibutuhkan oleh lebah, untuk menghasilkan madu sangatlah banyak antara lain mangga, kelapa, jagung, lengkeng, pisang, durian kenari dan lain sebagainya. Bahkan tidak menutup kemungkinan juga lebah mengambil makanan dari pohon tempat sarangnya berada.

Berdasarkan penelitian sebelumnya, Srinani, 2008 yaitu aktivitas antimikroba madu murni asal maros terhadap beberapa mikroba uji bahwa madu dengan konsentrasi 5\% aktiv menghambat pertumbuhan bakteri Bacillus subtilis, Salmonella thyposa, Pseudomonas aeruginosa, Sthapylococcus epidermidis, dan Staphylococcus aureus. Fathiyah pasisingi, 2008 yaitu aktivitas antimikroba madu lebah ternak (Apis mellifera) bunga kaliandra (Calliandra calothyrsus) terhadap beberapa bakteri uji, menunjukkan bahwa madu lebah ternak pada konsentrasi 2,5\% aktivitas menghambat pertumbuhan bakteri Bacillus subtilis, Salmonella thyposa, Staphylococcus aureus, Pseudomonas aeruginosa, dan Vibrio $s p$. Selanjutnya penelitian (Wineri et al., 2014) membandingkan daya hambat madu alami dengan madu buatan secara In Vitro terhadap bakteri, menunjukkan madu alami memiliki daya hambat lebih tinggi. Hal inilah yang mendasari perlu dilakukannya penelitian aktivitas antimikroba dengan metode KLTBioautografi pada madu hutan yang berasal dari selayar.

\section{Metode}

\section{Alat dan Bahan}

Alat-alat yang digunakan pada penlitian ini adalah cawan petri (Normax), chamber (Camag), corong pisah (Iwaki Pyrex), enkas, inkubator (Memmert), Laminar Air Flow (LAF), Lampu UV 254 nm dan $366 \mathrm{~nm}$ (Philips), mikropipet (Huawei), ose bulat, otoklaf (Smic), oven (Memmert), dan timbangan analitik (AND).

Bahan-bahan yang digunakan pada penelitian ini adalah alkohol 70\%, aquadest, almunium foil, biakan murni (Bacillus subtilis, Candida albicans, Escherichia coli, Staphylococcus aureus, Staphylococcus epidermidis, Streptococcus mutans, Salmonella typhi, Pseudomonasa aeruginosa, Vibrio sp,), DMSO (Dimetil Sulfoksida), lempeng TLC G60 F254, metanol, kloroform, n-butanol, medium GNA (Glukosa Nutrient Agar), sampel madu hutan (Apis nigrocincta) dari Kabupaten Selayar.

\section{Sterilisasi Alat}

Alat-alat yang digunakan dicuci hingga bersih dengan air suling, kemudian alat-alat gelas dikeringkan lalu dibungkus dengan kertas dan disterilkan dengan menggunakan oven pada suhu $180^{\circ} \mathrm{C}$ selama 2 jam. Alat-alat gelas yang berskala dan tidak tahan terhadap pemanasan dan yang terbuat dari plastik disterilkan dalam autoklaf pada suhu $121^{\circ} \mathrm{C}$ dengan tekanan $2 \mathrm{~atm}$ selama 15 menit. Ose disterilkan dengan cara dipijarkan pada lampu spiritus.

\section{Ekstraksi dan partisi.}

Sampel madu hutan (Apis nigrocincta) yang telah ditimbang sebanyak 61,71 gram madu hutan kemudian dipartisi cair-cair dengan pelarut n-butanol sebanyak $50 \mathrm{ml}$, kemudian diaduk sampai merata dengan sekali-kali membuka kran corong pisah kemudian diamkan sampai terjadi pemisahan dari fase air dan fase n-butanol, pisahkan fase air dan fase nbutanol. Kemudian fase air dimasukkan kembali ke dalam corong pisah dan diekstraksi lagi dengan nbutanol sebanyak $50 \mathrm{ml}$ dan diaduk sampai merata dengan sekali-kali membuka kran corong pisah kemudian diamkan sampai terjadi pemisahan dari fase air dan fase n-butanol, pisahkan fase air dan fase nbutanol. Hal ini diberi perlakuan yang sama hingga fase n-butanol terlihat jernih. Ekstrak n-butanol yang diperoleh dari beberapa kali penyarian disatukan kemudian diuapkan sampai mendapatkan ekstrak kental.

\section{Penyiapan Mikroba Uji.}

\section{a. Peremajaan mikroba uji.}

Bakteri uji diambil dari biakan murni masingmasing 1 ose. Kemudian diinokulasi dengan cara digoreskan pada medium agar miring Glukosa Nutrient Agar kemudian diinkubasikan pada suhu $377^{\circ} \mathrm{C}$ selama $1 \times 24$ jam untuk bakteri, dan pada suhu kamar selama $3 \times 24$ jam untuk jamur.

\section{b. Pembuatan suspense mikroba uji.}

Mikroba hasil peremajaan masing-masing disuspensikan dengan larutan $\mathrm{NaCl}$ fisiologi 0,9\% steril kemudian diukur serapan suspensi biakan itu dengan spektrofotometer pada panjang gelombang $580 \mathrm{~nm}$ dan dengan transmitan $25 \%$ untuk bakteri dan $75 \%$ untuk jamur sebagai blanko digunakan larutan $\mathrm{NaCl}$ fisiologis $0,9 \%$ steril. 


\section{Uji Skrining antiikroba.}

Ekstrak yang larut dan tidak larut dengan pelarut n-butanol yang digunakan pada madu hutan ditimbang $10 \mathrm{mg}$ lalu dilarutkan dengan DMSO sebanyak $0,2 \mathrm{ml}$. Setelah larut ekstrak ditambahkan medium GNA 9,8 $\mathrm{ml}$ sehingga diperoleh konsentrasi 1 $\mathrm{mg} / \mathrm{ml}$. Campuran tersebut dituang ke dalam cawan petri lalu dihomogenkan dan dibiarkan memadat. Suspensi bakteri digoreskan pada medium GNA yang telah memadat lalu diinkubasi selama $1 \times 24$ jam pada suhu $37^{\circ} \mathrm{C}$ untuk bakteri dan $3 \times 24$ jam pada suhu kamar $27^{\circ} \mathrm{C}$ untuk jamur.

\section{Identifikasi secara Kromatografi Lapis Tipis (KLT).}

Lempeng KLT diaktifkan dengan pemanasan dalam oven pada suhu $100^{\circ} \mathrm{C}$ selama 30 menit sebelum digunakan. Ekstrak n-butanol ditotolkan pada lempeng KLT ukuran $7 \times 1 \mathrm{~cm}$ menggunakan pipa kapiler. Lalu dielusi dengan menggunakan eluen kloroform : aseton $(3: 1)$ di dalam chamber. Lempeng dikeluarkan dari chamber dan diangin-anginkan hingga cairan pengelusinya menguap. Kemudian kromatogram yang dihasilkan diamati nodanya di bawah sinar UV pada panjang gelombang $254 \mathrm{~nm}$ dan $366 \mathrm{~nm}$, serta penampakan noda pada penyemprotan $\mathrm{H}_{2} \mathrm{SO}_{4} 10 \%$, diberi tanda yang menghasilkan flouresensi dan dihitung nilai Rf-nya.

\section{Pengujian secara KLT-Bioautografi}

Hasil identifikasi KLT dilanjutkan dengan uji KLT-Bioautografi dengan cara medium GNA steril sebanyak $10 \mathrm{ml}$ dituang ke dalam cawan petri yang telah berisi suspensi mikroba, lempeng KLT yang telah dielusi dengan eluen kloroform : aseton $(3: 1)$ diletakkan di atas permukaan medium agar yang agak memadat, dibiarkan selama 60 menit kemudian lempeng tersebut diangkat dan dikeluarkan. Selanjutnya media diinkubasi pada suhu $37^{\circ} \mathrm{C}$ selama 1 x 24 jam untuk bakteri dan pada suhu $27^{\circ} \mathrm{C}$ selama $3 \mathrm{x}$ 24 jam untuk jamur.

\section{Identifikasi Komponen Kimi}

Kromatogram disemprotkan dengan menggunakan beberapa pereaksi golongan komponen kimia yaitu :

a. Pereaksi flavanoid (Sutrisno, 1993)

1. Aluminium klorida

Lempeng disemprot dengan pereaksi $\mathrm{AlCl}_{3}$ dan diamati noda yang berflourosensi pada lampu UV 366, noda yang berflourosensi kuning atau hijau.

2. Antimon (III) klorida

Lempeng disemprot dengan pereaksi $\mathrm{SbCl}_{3}$ dan akan tampak bercak yang berpendar dalam sinar UV $366 \mathrm{~nm}$.
3. Tembaga sulfat-sitrat (Benedict)

Lempeng disemprot dengan pereaksi benedict, dan akan tampak bercak berpendar dalam sinar UV $366 \mathrm{~nm}$.

b. Pereaksi alkaloid (Sutrisno, 1993)

1. Dragendroff $-\mathrm{HCl}$

Lempeng disemprot dengan banyak pereaksi sampai penampakan warna noda orange.

2. Yodium - KI

Lempeng disemprot dengan banyak pereaksi sampai tampak tembus cahaya dengan warna noda orange kecoklatan.

3. Bauchardat

Setelah lempeng disemprot kemudian dikeringkan di udara sehingga menghasilkan tampak bercak berwarna coklat.

c. Pereaksi steroid (Sutrisno, 1993)

1. Liebermann-Burchard

Dipanaskan kromatogram dengan suhu $110^{\circ} \mathrm{C}$ selama 10 menit dan diamati noda yang berflouresensi pada lampu UV, noda yang berflouresensi biru adalah senyawa golongan steroid.

2. Vanilin-asam fosfat

Kromatogram disemprot dengan menggunakan pereaksi, kemudian dipanaskan kromatogram pada suhu $120^{\circ} \mathrm{C}$ sampai penampak bercak berwarna ungu.

3. Asam perklorat

Kromatogram disemprot dengan menggunakan pereaksi asam perklorat, kemudian lempeng disemprot deangan konsentrasi tinggi sampai tembus cahaya, kemudian dipanaskan pada suhu $120^{\circ} \mathrm{C}$ selama $15-30$ menit. Masing-masing jenis steroid memerlukan tempo pemanasan yang berbeda-beda untuk mencapai intensitas warna yang maksimal atau pendaran yang maksimal. Semua senyawa dari kelompok ini berpendar dalam sinar UV $366 \mathrm{~nm}$.

d. Pereaksi saponin (Sutrisno, 1993)

1. Komarowsky II

Campuran $1 \mathrm{ml}$ larutan asam sulfat 50\% (dalam etanol) dan $10 \mathrm{ml}$ larutan 4hidroksibenzaldehid 2\% (dalam etanol). Penanganan setelah disemprot, lempeng dipanaskan pada suhu $100^{\circ} \mathrm{C}$ selama 5-10 menit kemudian diamati dalam sinar biasa.

\section{Hasil dan Pembahasan}

\section{Pengujian skrining pelarut}

Setelah dilakukan uji skrining pelarut dengan menggunakan beberapa cairan penyari 
maka hasil yang didapatkan bahwa n-butanol yang paling banyak menghasilkan noda. Hasil uji skrining pelarut dapat dilihat pada tabel 1 dan gambar 2.

Tabel 1. Hasil Skrining pelarut

\begin{tabular}{clcc}
\hline \multirow{2}{*}{ No } & Cairan Penyari & \multicolumn{2}{c}{ Banyak Noda } \\
\cline { 3 - 4 } & & UV 254 & UV 366 \\
\hline 1 & Metanol & 6 & 4 \\
\hline 2 & Aseton & 6 & 3 \\
\hline 3 & Kloroforom & 6 & 2 \\
\hline 4 & N-butanol & 7 & 2 \\
\hline 5 & Etil asetat & 4 & 2 \\
\hline 6 & N-heksan & 2 & 2 \\
\hline
\end{tabular}

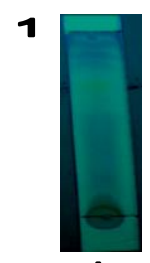

2

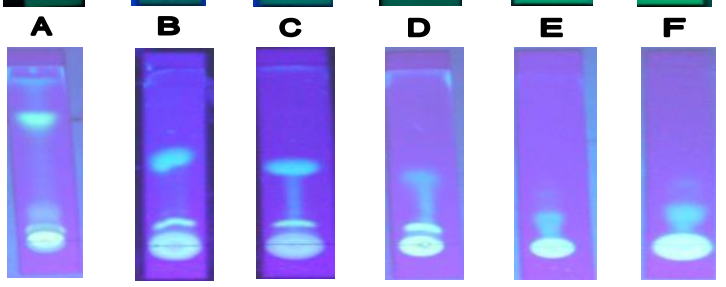

Gambar 2. Foto hasil pengujian skrining pelarut

Keterangan :

$\begin{array}{ll}1 & \text { : UV } 254 \\ 2 & \text { : UV } 366 \\ \mathrm{~A} & \text { : Metanol } \\ \mathrm{B} & \text { : Aseton } \\ \mathrm{C} & \text { : Kloroforom } \\ \mathrm{D} & \text { : N-butanol } \\ \mathrm{E} & \text { : Etil asetat } \\ \mathrm{F} & \text { : N-heksan } \\ \text { Eluen } & \text { : Kloroforom : Metanol }(1: 1)\end{array}$

Dari hasil skrining pelarut didapatkan $n-$ butanol yang memiliki noda yang paling banyak sehingga dilanjudkan proses ekstraksi dengan menggunakan metode partisi cair-cair. Diamana prinsip dari metode partisi cair-cair yaitu menggunakan dua pelarut yang tidak saling bercampur.

2. Hasil ekstraksi madu hutan (Apis nigrocincta)

Setelah dilakukan uji skrining pelarut ekstraksi madu hutan sebanyak 61,71 gram secara partisi menggunakan corong pisah dengan pelarut n-butanol maka diperoleh hasil 5,73 gram ekstrak n-butanol kental dan ekstrak fraksi air sebanyak 35,57 gram.
Tabel 2. Hasil Ekstraksi Madu Hutan (Apis nigrocincta)

\begin{tabular}{clc}
\hline No & \multicolumn{1}{c}{ Sampel } & $\begin{array}{c}\text { Bobot } \\
\text { (gram) }\end{array}$ \\
\hline 1 & $\begin{array}{l}\text { Madu Hutan (Apis } \\
\text { nigrocincta) }\end{array}$ & 61,71 gram \\
\hline 2 & Ekstrak n-butanol & 5,73 gram \\
\hline 3 & Ekstrak air & 35,57 gram \\
\hline
\end{tabular}

\section{Pengujian skrining antimikroba}

Setelah dilakukan uji skrining pada masing-masing ekstrak madu hutan (n-butanol) dan ekstrak air (residu) terhadap beberapa mikroba uji, yaitu Escherichia coli, Candida albicans, Staphylococcus aureus, Pseudomonas aeruginosa, Vibrio cholera, Bacillus subtilis, Streptococcus mutans, Salmonella typhi, dan Staphylococcus epidermidis. Maka diperoleh hasil bahwa ekstrak n-butanol menunjukan aktivitas antimikroba terhadap bakteri uji Escherichia coli, Bacillus subtilis, Staphylococcus aureus, dan Staphylococcus epidermidis. Data selengkapnya dapat dilihat pada tabel 3.

Tabel 3. Hasil Pengujian Skrining Aktivitas Antimikroba Sampel Madu Hutan (Apis nigrocincta)

\begin{tabular}{|c|c|c|c|c|c|c|c|c|c|}
\hline \multirow[t]{3}{*}{ Sampel } & \multicolumn{9}{|c|}{ Mikroba Uji } \\
\hline & B & $\mathrm{S}$ & $S$ & $\mathrm{~S}$ & E & $\mathrm{P}$ & $\mathrm{S}$ & V & C \\
\hline & 5 & $\mathrm{~T}$ & $\mathrm{M}$ & E & C & A & A & C & A \\
\hline $\begin{array}{l}\text { Ekstrak } \\
\text { n- } \\
\text { butanol }\end{array}$ & + & - & - & + & + & - & + & - & - \\
\hline $\begin{array}{l}\text { Ekstrak } \\
\text { air }\end{array}$ & - & - & - & - & - & - & - & - & - \\
\hline $\begin{array}{l}\mathrm{K}(+) \\
\text { Antibak } \\
\text { teri }\end{array}$ & + & + & + & + & + & + & + & + & \# \\
\hline $\begin{array}{l}\mathrm{K}(+) \\
\text { Antijam } \\
\text { ur }\end{array}$ & \# & \# & \# & \# & \# & \# & \# & \# & + \\
\hline $\mathrm{K}(-)$ & - & - & - & - & - & - & - & - & \\
\hline
\end{tabular}

Keterangan:
BS

ST

SM

SE

EC

PA

SA

VC

CA

$\mathrm{K}(+)$ Antibakteri
: Bacillus subtilis

: Salmonella typhi

: Streptococcus mutans

: Staphylococcus epidermidis

: Escherichia coli

: Pseudomonas aeruginosa

: Staphylococcus aureus

: Vibrio cholera

: Candida albicans

:Kontrol positif antibakteri

(Kloramfenikol) 

K (+) Antijamur
:Kontrol positif antibakteri
(Ketokonazol)
K (-)
$(-)$
: Kontrol negative (DMSO)
: Menghambat pertumbuhan mikroba
: Tidak menghambat
pertumbuhan mikroba

Dari hasil uji skrining aktivitas antimikroba menunjukan bahwa ekstrak air dengan konsentrasi $1 \mathrm{mg} / \mathrm{ml}$ tidak menunjukan adanya hambatan terhadap mikroorganisme yang diujikan, sedangkan ekstrak n-butanol madu hutan (Apis nigrocincta) memberikan hambatan terhadap pertumbuhan bakteri Bacillus subtilis, Escherichia coli, Staphylococcus aureus, dan Staphylococcus epidermidis, sehingga potensial dari ekstrak n-butanol perlu diteliti lebih lanjut aktivitas antimikrobanya.

\section{Kesimpulan}

Berdasarkan hasil yang diperoleh dari penelitian yang telah dilakukan terhadap madu hutan (Apis nigrocincta), maka dapat disimpulkan bahwa ;

1. Ekstrak n-butanol madu hutan (Apis nigrocincta),memberikan hambatan terhadap pertumbuhan mikroba.

2. Pada metode KLT-Bioautografi memperlihatkan 1 bercak aktif yang mempunyai efek sebagai antimikroba dengan nilai Rf 0,29.

3. Komponen kimia aktif antimikroba menunjukan positif pada penampak bercak terhadap golongan senyawa flavonoid.

Untuk penelitian selanjutnya sebaiknya dilakukan isolasi dan identifikasi komponen kimia madu hutan (Apis nigrocincta) yang berkhasiat sebagai antimikroba.

\section{Daftar Pustaka}

Dewi, i. S. (2018). Analisis kelayakan finansial budidaya lebah madu di desa kuapan kecamatan tambang kabupaten kampar (kasus usaha madu "mekar sari"). Jurnal agribisnis. Https:// doi.org/10.31849/agr.v20i1.1495

Hadisoesilo, s. (2001). The Diversity of Indigenous Honey Bee Species of Indonesia. Biodiversitas, Journal of Biological Diversity. https://doi.org/10.13057/biodiv/d020107.

Murtidjo, B., 1991., Memelihara Lebah Madu., Kanisus,Yogyakarta.
Rahalison, L., Hostcman. K, 1991., A Bioautographis Agar Overlay Method for The Detection of Antifongal Compounds for Higher Plants Phykochemical Analysis, Vol. 2 University de Laausanne Swtecrland.

Rostita., 2007., Madu Sehat Cantik dan Penuh Vitalis., PT Mizan Pustaka, Bandung.

Sutrisno.R., 1993., Pereaksi KLT., Fakultas Farmasi Universitas Pancasila, Jakarta.

Tobo, F., Mufidah, Taebe, B dan Mahmud, I., 2001., Buku Pegangan Laboratorium Fitokimia I (Ekstraksi Komponen Kimia Bahan Alam). Laboratorium Fitokimia Jurusan Farmasi, FMIPA., Universitas Hasanuddin, Makassar.

Wiryowidagdo., S., 1990., Penelitian dan Pengembangan Obat Tradisional Dalam Pengobatan Modern., Penelitian Regional Peningkatan Peran Serta Masyarakat Bagi Petugas Dati II Dalam Pembinaan Upaya Kesehatan Tradisional. Ujung Pandang

Wineri, E., Rasyid, R., \& Alioes, Y. (2014). Perbandingan Daya Hambat Madu Alami dengan Madu Kemasan secara In Vitro terhadap Streptococcus beta hemoliticus Group A sebagai Penyebab Faringitis. Jurnal Kesehatan Andalas. https://doi.org/10.25077/jka.v3i3.140 